\title{
3D Parametric Modelling of Milling Cutter Geometry from Analytical Analysis
}

\author{
A. Nasri ${ }^{1,2, ~ *, ~ J . ~ S l a i m i ~}{ }^{1,2}$,W. Bouzid Sai ${ }^{2}$ \\ ${ }^{1}$ Department of Mechanical Engineering, University of Tunis El Manar, National Engineering School of Tunis, Tunis, Tunisia \\ ${ }^{2}$ National Engineering School of Sfax, Sfax, Tunisia \\ Email address: \\ abdallah.nasri@enit.rnu.tn (A. Nasri) \\ ${ }^{*}$ Corresponding author
}

To cite this article:

A. Nasri, J. Slaimi, W. Bouzid Sai. 3D Parametric Modelling of Milling Cutter Geometry from Analytical Analysis. International Journal of Science, Technology and Society. Vol. 4, No. 2, 2016, pp. 35-40. doi: 10.11648/j.ijsts.20160402.13

Received: October 24, 2015; Accepted: November 9, 2015; Published: April 12, 2016

\begin{abstract}
Numerical simulation of milling process needs an accurate model of cutting tool. In this paper, we describe the methodology developed to design flat and ball end mills in three-dimensional configuration. The geometry of these cutters is issued from an analytic study based on oblique cutting theory. The described model is performed by using parametric CAD software. Hence, it involves a big number of variables as the diameter, the helix, the rake and the clearance angles and the teeth number. Furthermore, the modelled cutters are compared to real scanned ones in order to validate the used methodology. The results show a good accuracy regarding the global three-dimensional shape.
\end{abstract}

Keywords: Milling Cutter, CAD Modelling, Digitizing Techniques

\section{Introduction}

As milling is one of the most frequently used machining processes, the knowledge of its optimal cutting parameters is essential. Many investigations are conducted, in this context, to model cutting forces, temperature distribution, chip morphology, machined parts quality and tool life. In their works, researchers pay more attention, commonly, to study the effect of tool geometry because of its complexity and the intermittent character of the milling process, by using analytical modelling with simplified hypothesis, numerical analysis or/and experimental approaches.

Gradisek and et al. [1] presented expressions for mechanistic identification of cutting force coefficients for a general helical end mill based on a generalized mathematical model of the outer cutter, developed by Engin [2], and which is valid for a variety of end mill shapes, such as cylindrical, taper, ball nose, etc.

In the same context, a predictive force model for ball-end milling based on thermomechanical modelling of oblique cutting was expressed by Fontaine [3]. The tool geometry is decomposed into a series of axial elementary cutting edges. At any active tooth element, the chip formation is obtained from an oblique cutting process characterised by local undeformed chip section and local cutting angles.

Ben Said and et $a l$. [4] proposed later an analytical model to estimate the cutting forces and the tool geometry in relation to the flank wear when milling with a ball-end mill.

Moreover, in his work including instantaneous cutting forces and finished workpiece topography in ball end milling, Lazoglu [5] mentioned that the mill cutting edge geometry can be represented either by an explicit mathematical model supplied by cutter manufacturer or via polynomial fitting to CMM data set.

Although the accuracy of the above mentioned ways to model the milling cutter geometry, it is believed that the use of graphical and numerical approaches is better since it offers visual information and three-dimensional representation of the cutting process.

In the literature, one can mainly distinguish two methods to represent the milling cutter. In the first one, the tool is replaced by graphical entities (cylinder or/and sphere) [5-7], and thus, the milling process is materialized by only the undeformed chip and one can rule out the influence of the geometric parameters of the cutter such as the rake and flank angles.

In the second method, in order to simulate the milling 
process with numerical analysis, authors are constrained to reproduce the 3D model of the milling cutter as an element of the global model geometry including essentially the tool and the workpiece.

Soo et al. [8] developed a three-dimensional finite element model of the ball nose end milling process, using ABAQUS Explicit to demonstrate the high-speed machining of Inconel 718 superalloy. In this work, Ball nose end mill geometry was based on commercial tools and was created externally on a computer aided design system (AutoCAD) and imported into the FE domain.

Pantalé [9] presented a three-dimensional oblique model to simulate the unsteady-state process of chip formation in a milling application. In this model, performed with finite elements package Abaqus, only a part of the twist milling cutter has been modeled to reduce the number of elements.

In the work of Fontaine [10], a 3D FEM model of shoulder milling on a $304 \mathrm{~L}$ stainless steel has been developed with the LS-Dyna commercial software. The used tool geometry was obtained from a digitalized model of a real milling cutter by using a $3 \mathrm{D}$ reconstruction technique.

Nasri [11] proposed a 3D steady-state FE model to simulate the temperature distribution in ball end milling. The geometry of the 3D model, including the chip, the workpiece, the shear zones and the tool, is designed on CAD package (CATIA) based on experimental and analytical modelling of the ball end mill.

Recently, Diciuc [12] presented a review of the main modelling types of the cutting process using ball nose end mills, underlining the specificity, the advantages and disadvantages for each type.

The purpose of this work is to generate $3 \mathrm{D}$ parametric models of flat and ball end milling cutters by using parametric CAD software, to be integrated in FE simulation studies of

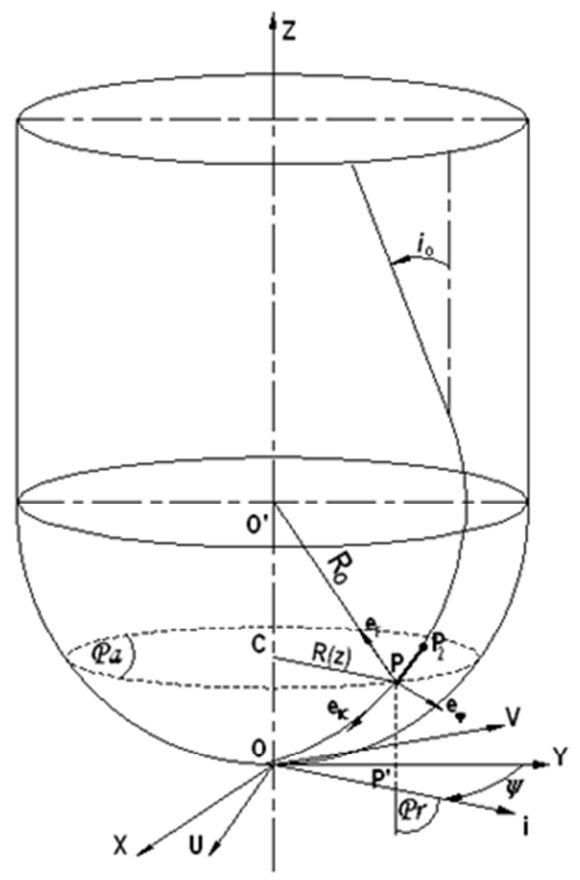

milling process.

The paper is organized as follows: Section 2 presents a brief review of the analytical modelling of milling cutter geometry; in Section 3, the methodology used to design the parametric model is developed for both flat and ball end mills. Finally, Section 4 describes the experimental technique used to rebuild real mills and the comparison between $3 \mathrm{D}$ reconstructed and developed models.

\section{Analytical Modelling of Milling Cutter Geometry}

End milling cutters are multi-point cutters with cutting edges both on the end face and the circumferential surface of the cutter [13]. In the following, we will focus our interest only on the ball and flat end mills.

Fig. 1 details the geometry of ball end mill defined in a coordinate system $(\mathrm{O}, \vec{X}, \vec{Y}, \vec{Z})$ where $\mathrm{O}$ is the tool tip. The tool envelope is composed by a cylindrical surface and a spherical surface having both the same radius $R_{0}$. The cutting edge is considered helix with constant lead. In the cylindrical part, the helix angle is constant and noted $i_{0}$.

For a cutting point $\mathrm{P}$ at height $\mathrm{z}$, a local spherical coordinate $\operatorname{system}\left(\mathrm{P}, \overrightarrow{e_{r}}, \overrightarrow{e_{\kappa}}, \overrightarrow{e_{\psi}}\right)$ is defined (Fig. 1-a).

The orthogonal projection of $\mathrm{P}$ on the plane $(\mathrm{O}, \vec{X}, \vec{Y})$ corresponding to the plane $\mathrm{Pa}$, is noted $\mathrm{P}$ '. The plane joining the points $\mathrm{O}, \mathrm{P}$ and $\mathrm{P}$ ' corresponds to the reference plane $\mathrm{Pr}$ (Fig. 1-b).

With respect to the directions $\overrightarrow{e_{r}}, \overrightarrow{e_{\kappa}}$ and $\overrightarrow{e_{\psi}}$, the point $\mathrm{P}$ is located on the cutting edge $j$ by its spherical coordinates $R_{0}, \kappa$ and $\psi$ as defined on the planes $\mathrm{Pr}$ and $\mathrm{Pa}$.

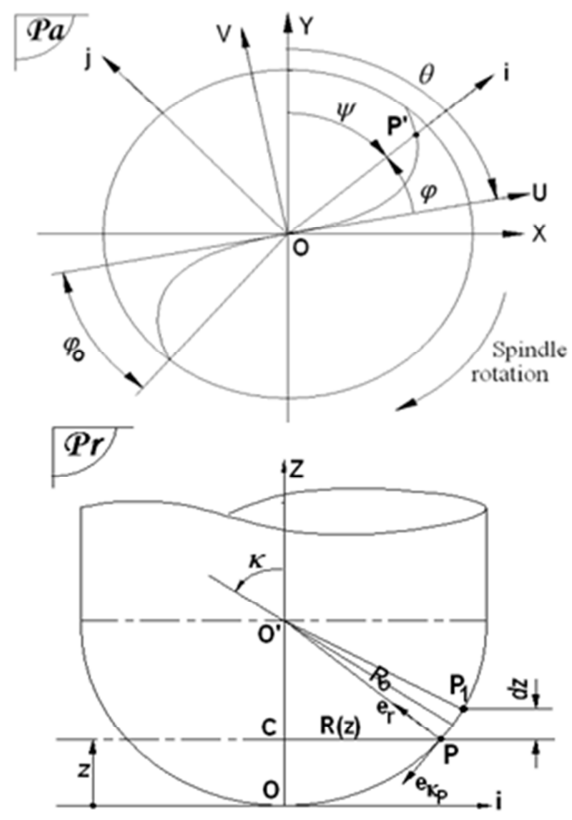

Fig. 1. Ball end mill geometry, (a)- global geometry, (b)- local geometry. 
These angular positions can be written as following:

$$
\begin{gathered}
\cos \kappa(z)=\frac{R_{0}-z}{R_{0}} \\
\psi(\theta, z)=\theta+(j-1)\left(2 \pi / N_{f}\right)-\varphi(z)
\end{gathered}
$$

where $\theta$ is the rotation angle of the mill, $N_{f}$ is the number of teeth and $\varphi(\mathrm{z})$ is the lag angle measured between the tool tip and the current point $\mathrm{P}$ and expressed as:

$$
\varphi(z)=\frac{z \tan i_{0}}{R_{0}}=\frac{z \tan i(z)}{R(z)}
$$

Thus, the local helix angle $i(z)$ can be written as:

$$
\tan i(z)=\frac{R(z)}{R_{0}} \tan i_{0}
$$

$R(z)$ is expressed as:

$$
R(z)=R_{0} \sqrt{1-\left(\frac{z}{R_{0}}-1\right)^{2}}
$$

The orthogonal projection of another cutting point $\mathrm{P}_{2}$ (Fig. 1-a) on Pr corresponds to the drawn point $\mathrm{P}_{1}$ on Fig. 1-b. $d z$ is the incremental distance between $\mathrm{P}$ and $\mathrm{P}_{1}$.

The modelling of the flat end mill geometry is issued from the study established above since we consider only the cylindrical part of the tool. The helix angle and the cutter radius remain both constant.

\section{Model Design Methodology}

For both end mill types, the technique used to design the three-dimensional model is sweeping and rotating an initial cross-sectional profile of the cutter along the $\mathrm{Z}$ direction.

\subsection{D Flat End Mill Model}

For a given cutting point $\mathrm{P}$ at height $\mathrm{z}$, a simplified cross-sectional profile (CSP) of the flat end milling cutter is represented in Fig. 2, where $\gamma_{a}$ and $\alpha_{a}$ are respectively the rake and the clearance angles in a plane $\mathrm{Pa}$ chosen at an initial height $z=L$ where $L$ corresponds to the length of cut.

As shown in Fig. 3 the $3 \mathrm{D}$ model is obtained, first, by sweeping the initial CSP1 along the orthogonal direction with the incremental distance $d z$, then, rotating with a constant elementary position angle $d \psi(\mathrm{z})$.

By using the CAD package CATIA, we obtained the three-dimensional model presented in Fig. 4, for the following characteristics of the milling cutter:

$L=40 \mathrm{~mm}, d z=1 \mathrm{~mm}, N_{f}=2$ teeth, $R_{0}=5 \mathrm{~mm}, \theta=0 \mathrm{deg}$, $\gamma_{a}=10 \mathrm{deg}, \alpha_{a}=10 \mathrm{deg}$ and $i_{0}=25 \mathrm{deg}$.

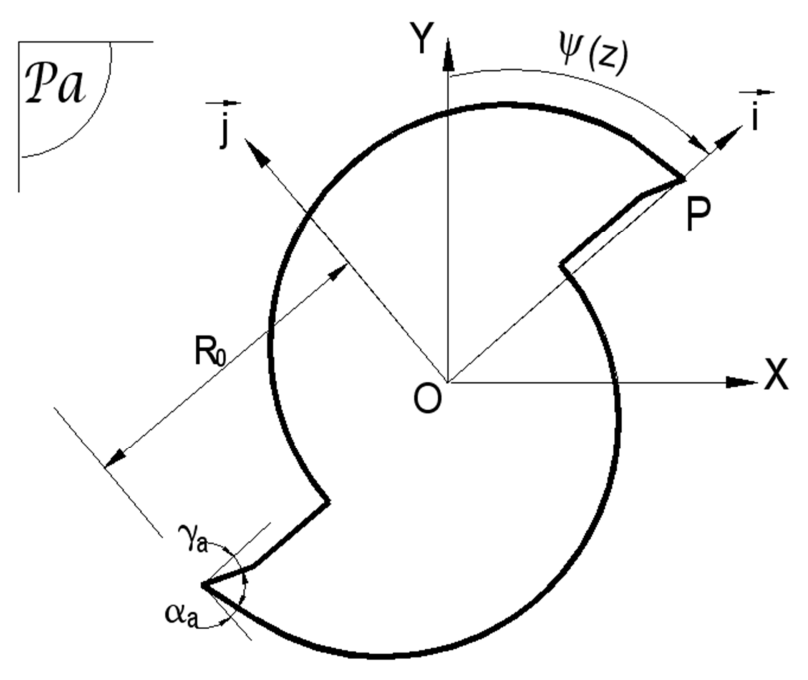

Fig. 2. 2D cross-sectional profile.

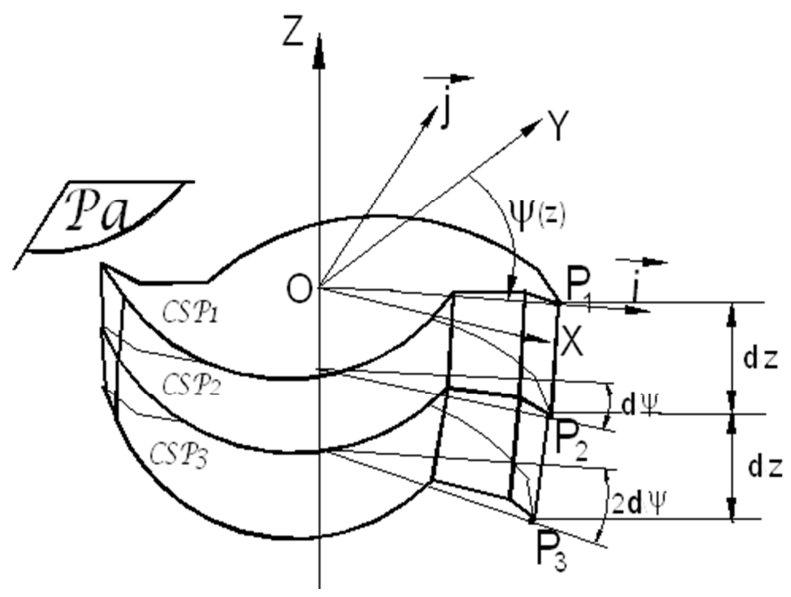

Fig. 3. 3D model design technique.

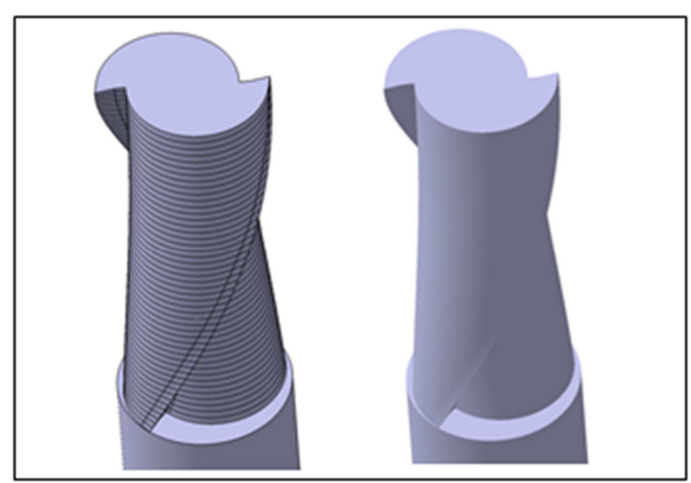

Fig. 4. Designed $3 D$ flat end mill.

\subsection{D Ball End Mill Model}

As mentioned in Section 2, the ball end mill (BEM) is composed by a cylindrical surface and a spherical surface having both the same radius $R_{0}$.

To design the cylindrical part, the technique used is the same described before for the flat end mill. 


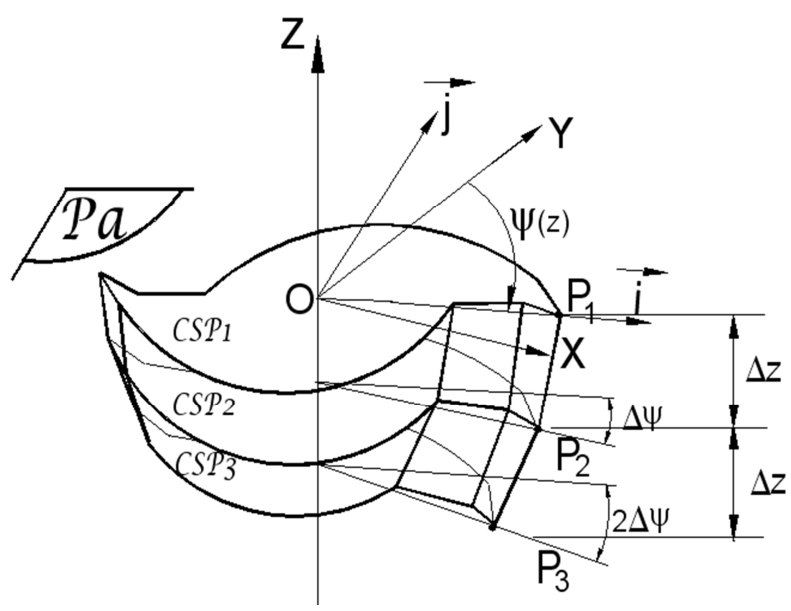

Fig. 5. BEM model design technique.

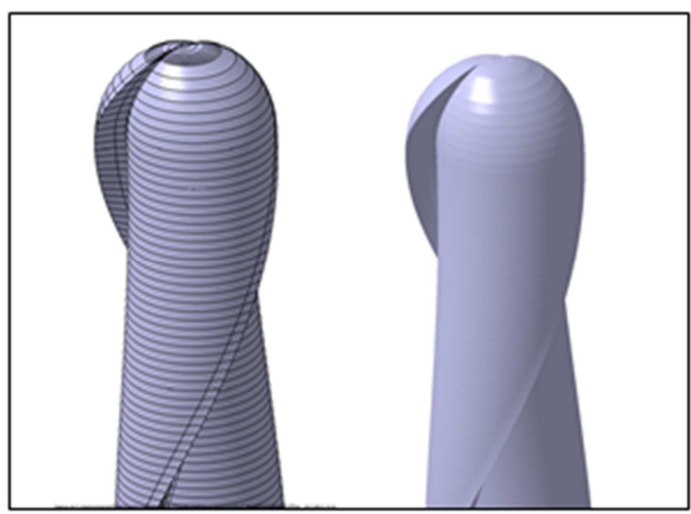

Fig. 6. Designed $3 D$ ball end mill.

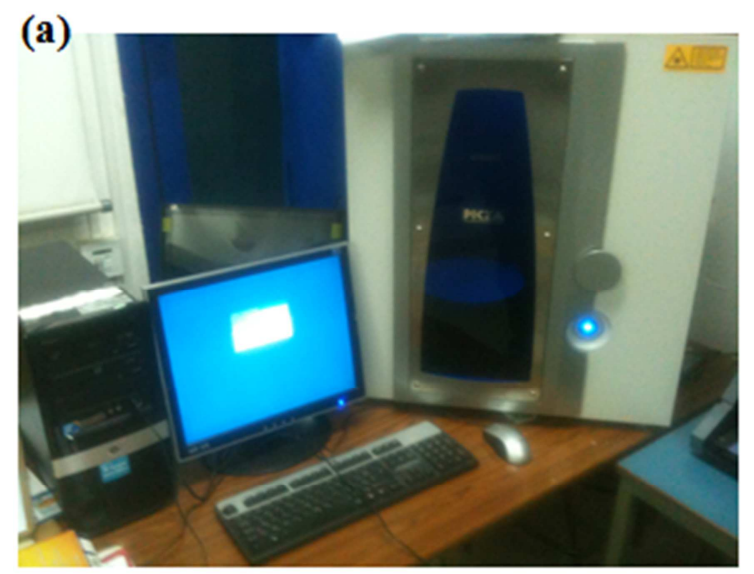

The spherical part results from the junction of iterative 2D shapes obtained by sweeping and rotating an initial cross-sectional profile (CSP) of the ball end cutter given at an initial height $z=R_{0}$ taking into account at each iteration a CSP reduction ratio (Fig. 5).

The CSP radius at any instance $\mathrm{z}$, is $R(z)$. The ratio by witch the CSP reduces while moving towards the tip of the ball end cutter is $R(z) / R_{0}$.

The obtained model for: $N_{f}=2$ teeth, $R_{0}=5 \mathrm{~mm}, \theta=0 \mathrm{deg}$, $\gamma_{a}=10 \mathrm{deg}, \alpha_{a}=10 \mathrm{deg}$ and $i_{0}=25 \mathrm{deg}$ is presented in Fig. 6 .

\section{The Model Validation}

To examine the validity of the above-mentioned technique, an experimental methodology was performed. This methodology consists on rebuilding 3D milling cutters in order to check the real geometry and to compare it to the developed model.

\subsection{Experimental Approach}

To digitize the milling cutters, a laser scanner PICZA LPX 800 was used. This set up working with spot-beam triangulation scanning method has a resolution of $0.2 \mathrm{~mm}$. The digitizing operation is controlled from Pixform Pro II software (Fig. 7-a).

Seen the mill revolved geometry, the rotary scanning mode was adopted (Fig. 7-b).

A dry powder developer is applied first to the mill surface. Then, once placed in the rotating table, a laser beam travels vertically up the tool to generate a digital data file.

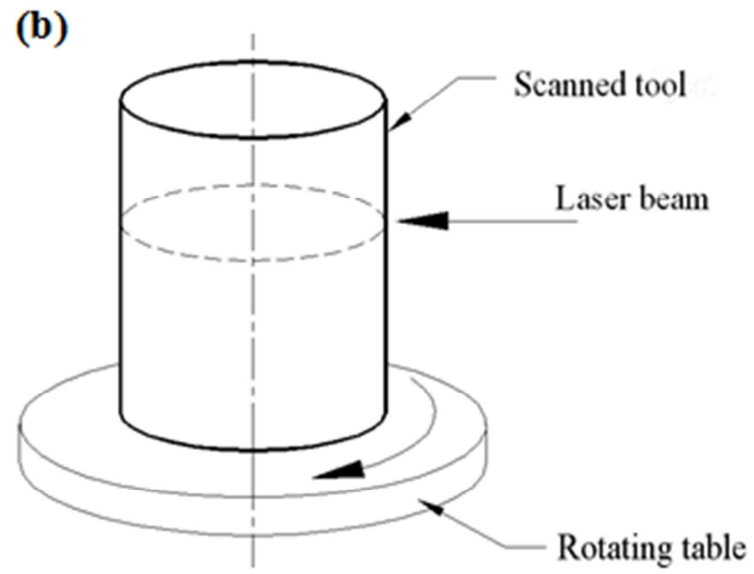

Fig. 7. (a) Experimental set up and (b) schema of scanning mode principle.

\subsection{Scanning Results and Discussion}

Table 1. Used tools characteristics.

\begin{tabular}{llllll}
\hline Type & Code & $\begin{array}{l}\text { Radius } \\
\mathbf{R}_{\mathbf{0}}(\mathbf{m m})\end{array}$ & $\begin{array}{l}\text { Helix angle } \\
\mathbf{i}_{\mathbf{0}}(\mathbf{d e g})\end{array}$ & $\begin{array}{l}\text { Rake } \\
\text { angle } \boldsymbol{\gamma}_{\mathbf{a}} \\
\mathbf{( d e g )}\end{array}$ & $\begin{array}{l}\text { Length of } \\
\text { cut } \mathbf{L} \\
\mathbf{( m m )}\end{array}$ \\
\hline Flat end & $\mathrm{C} 110$ & 6 & 30 & 12 & 27.5 \\
Ball end & \multirow{2}{*}{ C500 } & 8 & 30 & 12 & 30 \\
& & 4 & 30 & 12 & 20 \\
\hline
\end{tabular}

(a)

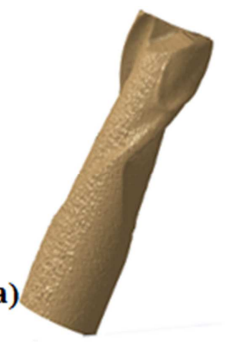

(b)
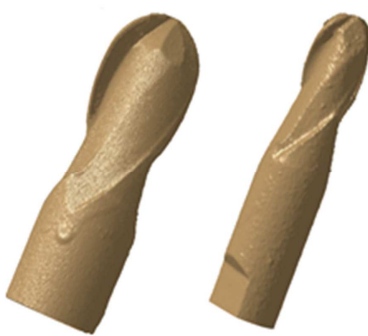

Fig. 8. Scanned milling cutters (a) flat end mill, (b) ball end mills. 
Three commercial Dormer HSS tools are used in this experiment. Their characteristics are shown in Table 1 [14].

Once the digitizing process is terminated, the obtained data file containing a point cloud is exported to CAD software CATIA where these points are cleaned and converted to surfaces representing finally the models shown in Fig. 8.

\subsection{Comparison Between Digitized and Developed Models}

As mentioned earlier, the CAD developed milling cutter model is parametric.

The identified input variables that determine its 3D geometry are mainly:

- tool radius $R_{0}$;

- helix angle $i_{0}$;

- rake and clearance angles $\gamma_{a}$ and $\alpha_{a}$;

- length of cut L;

- teeth number $N_{f}$.

In order to reproduce the same scanned mills, these parameters are set to the values presented in table 1 .

A 3D comparison between CAD and digitized models is then done (Fig. 9).

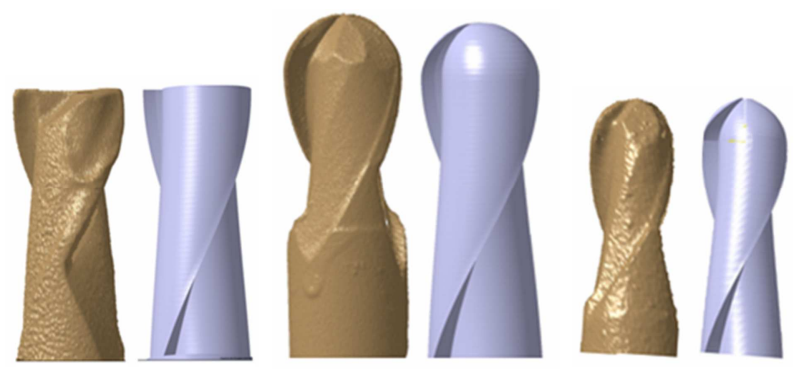

Fig. 9. 3D comparison between CAD and scanned milling cutters.

Fig. 9 shows that the 3D shapes of the scanned and designed milling cutters are very similar for all the configurations with a good reproduction of the main tool characteristics which are the radius and the helix angle. However, it can be noted that a difference exists between the shapes of helical flutes.

To further illustrate this difference, a $2 \mathrm{D}$ comparison is performed, on Fig. 10, between two cross section profiles, obtained at the same height $\mathrm{z}$, and corresponding respectively to ball end digitized and CAD designed models.
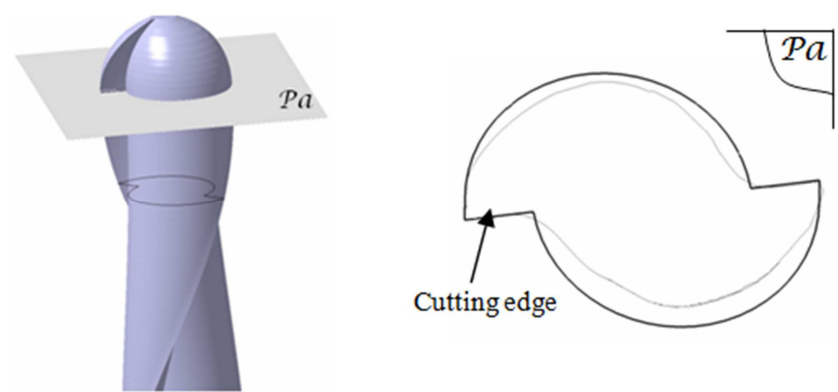

Fig. 10. 2D comparison between digitized and designed cross section profiles.

Furthermore, as one can notice, Fig. 10 shows a good accuracy regarding the cutting edge location and the rake and clearance angles values.
In summary, the observed agreement between the modelled and the digitized models validates the used design technique although the difference noticed between the flute shapes. Moreover, this difference has no effect on the cutting process if known that only the rake face is in contact with the workpiece material.

\subsection{FEM Modelling}

As stated earlier, the presented study is a precursor for modelling end milling process where the model geometry includes the geometry of the cutter.

This section describes an initial work concerning the tool meshing aspects carried out on commercial FE Software Abaqus.

CATIA software is utilised to convert the milling cutter model into an IGES format solid model.

Fig. 11 illustrates the initial mesh of the model.

The end mill is modelled as a rigid body using tetrahedral rigid elements.

As can be seen, the proposed model is well adapted to the meshing process thanks to the simplified shapes used in the cross-sectional profile.

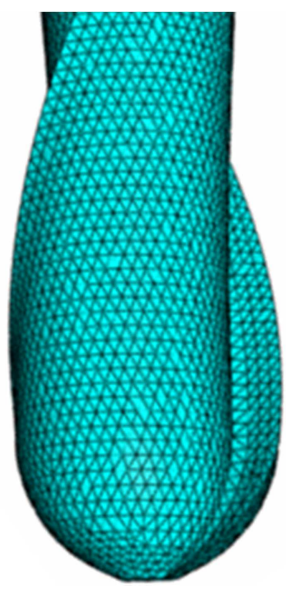

Fig. 11. Initial mesh of the ball end mill model.

\section{Conclusion}

In numerical simulation of end milling process, the model geometry including the cutter model is needed.

In the present paper, 3D parametric models of flat and ball end mills are developed from an analytical analysis of the milling cutter geometry taking into account a number of variables as tool radius, helix angle, rake and clearance angles.

To validate the proposal CAD model a digitizing process was performed. The comparison between both scanned and developed models shows a good agreement between, not only the $3 \mathrm{D}$ shapes but also the location of the cutting edge and rake and clearance angles. The difference detected around the flute shapes has no effect, later, on the simulation results.

Moreover, no problems were encountered when converting and exporting the CAD model to FE software package where regular meshing was developed. 


\section{References}

[1] Gradisek J., Kalveram M., Weinert K. (2004). Mechanic identification of specific force coefficients for general end mill, International Journal of Machine Tools and Manufacture, Vol. 44, pp. 401-414.

[2] Engin S., Altintas Y. (2001). Mechanics and dynamics of general milling cutters. Part I: helical end mills, International Journal of Machine Tools and Manufacture, Vol. 41, pp. 2195-2212.

[3] Fontaine N., Devillez A., Moufki A., Dudzinski D. (2006). Predictive force model for ball-end milling and experimental validation with a wavelike form machining test, International Journal of Machine Tools and Manufacture, Vol. 46, pp. 367-380.

[4] Ben Said M., Saï K., Bouzid Saï W. (2009). An investigation of cutting forces in machining with worn ball-end mill, Journal of Materials Processing Technology, Vol. 209, pp. 3198-3217.

[5] Lazoglu I., (2003). Sculpture surface machining: a generalized model of ball-end milling force system, International Journal of Machine Tools and Manufacture, Vol. 43, pp. 453-462.

[6] Bouzakis K.-D., Aichouh P., Efstathiou K. (2003). Determination of the chip geometry, cutting force and roughness in free form surfaces finishing milling, with ball end tools, International Journal of Machine Tools and Manufacture, Vol. 43, pp. 499-514..
[7] Diciuc V., Lobontiu M., Nasui V. (2011). The modeling of the ball nose end milling process by using CAD methods, Academic Journal of Manufacturing Engineering, Vol. 9, pp. 42-47.

[8] Soo S L, Aspinwall D K, Dewes R C (2004). Three-dimensional finite element modelling of high-speed milling of Inconel 718, Proceedings of the Institution of Mechanical Engineers, Vol. 218, pp. 1555-1561.

[9] Pantale O., Bacaria J. L., Dalverny O., Rakotomalala R., Caperaa S. (2004). 2D and 3D numerical models of metal cutting with damage effects, Computer Methods in Applied Mechanics and Engineering, Vol. 193, pp. 4383-4399.

[10] Fontaine M., Lambert-Campagne L., Maurel-Pantel A. (2009). Reconstruction 3D d'outils coupants pour le contrôle géométrique des fraises et la modélisation du fraisage, 19ème Congrès Français de Mécanique, Marseille.

[11] Nasri A., Ben Said M., Bouzid Sai W., Tsoumarev O. (2011). Numerical simulation of temperature distribution in a 3D ball end milling model, International Journal of Machining and Machinability of Materials, Vol. 9, pp. 209-222.

[12] Diciuc V., Lobontiu M. (2014). A review of the main modeling methods for ball nose end milling process, Applied Mechanics and Materials, Vol. 657, pp. 93-97.

[13] Drodza T. J., Wick C. (1983). Tool and Manufacturing Engineers Handbook, Vol. I, Machining Society of Manufacturing Engineers, Dearborn, MI.

[14] Precision Dormer Catalog (2012). 